\title{
PERFORMANCE EVALUATION OF AUTOMATED IMPLEMENT FOR VINEYARD MECHANICAL WEED CONTROL
}

\author{
Marco Sozzi ${ }^{1}$, Eddy Pasquetti ${ }^{2}$, Angelica De Ros ${ }^{1}$, Filippo Ferro ${ }^{1}$ \\ ${ }^{1}$ University of Padova, Italy; ${ }^{2}$ IIS Alberto Parolini, Italy \\ marco.sozzi@phd.unipd.it, eddy.pasquetti@studenti.unipd.it, angelica.deros@studenti.unipd.it , \\ filippo.ferro.1@studenti.unipd.it
}

\begin{abstract}
Weed control is an important management practice for sustainable grape production since grass coverage can change nutritional and water balance of vines. Although inter-row grass is used to reduce soil erosion and reduce vine vigour, under-row grass is usually undesirable. Chemical, mechanical, and thermal weeding systems are commonly used for under-row grass control. Over the last few years, the technological advance in vineyard mechanization led to new solution as an alternative to chemical-based weed control. Such systems take advantage of different type of sensors and feeler to manage the tillage implement close to vine trunk. In this study, a sensor-driven tillage system was evaluated and compared to manual management of the same tillage implements for weed control. Mechanical weeding was performed with a rotary star tiller controlled by a laser scanner system (LIDAR). Automated and manual working configurations were evaluated in terms of effective field capacity (ha. $\mathrm{h}^{-}$ ${ }^{1}$ ) and uniformity of tilled soil from vines trunk. Effects of the automated system on tillage implements were evaluated with accelerometers. According to the result, the sensor driver implement allows in increments of working speed of $29.4 \%$. At the same time, the average variation of tilled soil was $3.8 \mathrm{~cm}$ with the automated system and 8.1 with manual management of tillage implements. The results of this study showed that the automated system can be used to increase the field capacity and uniformity of mechanical weeding.
\end{abstract}

Keywords: precision viticulture, LiDAR, tillage, viticulture strategy, weed control.

\section{Introduction}

Sustainable weed control is an important practice to decrease environmental footprint of grape production. Over the last few years several management practises were proposed as an alternative to chemical-based weed control [1]. Mechanical weed control can be used for weeding under vine rows, causing additional benefits reducing nitrogen leaching [2]. Tillage implements require specific devices to avoid damage to vine trunk [3]. These solutions require reduced speed and decrease the effective field capacity [4]. Moreover, quality of tillage operation may be negatively affected by reduced speed with passive implements. Despite the reduced speed required, mechanical weed control is more cost-effective than chemicals application [5]. Several robot solutions were proposed in the last few years, which are characterized by autonomous vehicles able to remove weed [6]. Although these innovations represent novelty in vineyard mechanisation, their implementation in commercial farms is still reduced. The current study was undertaken to investigate working and agronomic performance of LiDAR driven tillage implements for weed control in vineyard. This sensor can be mounted on a tractor to manage tillage and weeding implements. The movements of implements close to vine trunk are managed by the LiDAR sensor, allowing the driver to focus on steering. In this study automated tillage for weed control was compared to manual management of tillage implements mounted on the tractor. The implementation of real-time application based on sensors represent an important application of precision agriculture [7], which takes advantage of variable rate application without the limitation of remote sensors [8].

\section{Materials and methods}

The study was conducted on a cluster of 18 rows of vines. Vines were trained as free cordon with a row space of 2.7 metres and a space between plants of 1.2 metres $\left(\simeq 3085\right.$ plants $\cdot h^{-1}$ ectares). In three rows, automated rotary star tiller was tested, while in other three rows the rotary star tiller was managed manually. For each treatment three repetition were performed. During the tillage operation working and manoeuvre times were recorded, while tillage quality was assessed in ten points for each treatment and repetition. This experimental design is shown in Figure 1.

Mechanical weeding was performed using a ventral rotary star tiller with two disks (Rollhacke, Braun Maschinenbau, Landau/Pfalz, Germany) [9]. This system is composed by a hydraulic lifter with springs. The disks system was connected to the hydraulic lifter thanks to a bracket with tilt and angle adjustment. This two disk system allows loosening the soil along the vines. Aggressivity and working width of tillage operations can be managed changing the tilt and angle of the disk system on the bracket. 
In the working configuration of this study the angle and tilt were settled to achieve a working width of $170 \mathrm{~mm}$. Variable working width mulcher was utilized at the same time, even if it was not evaluated in the study. In manual configuration, the rotary star tiller position was settled one time before the tillage operation. In the automated configuration, the Vineyard Pilot Assistant (VPA) system (Braun Maschinenbau, Landau/Pfalz, Germany) was used to manage implements positions. VPA was composed by a LiDAR sensor mounted in front of the tractor (Fendt $211 \mathrm{~V}$, AGCO, Duluth, USA). This LiDAR sensor is connected to an electronic control unit, which managed hydraulic cylinders according to trunks and plant positions detected by the sensor. This system adjusts the implement movements according to their relative position from the vines. Figure 2 represents the whole working configuration.

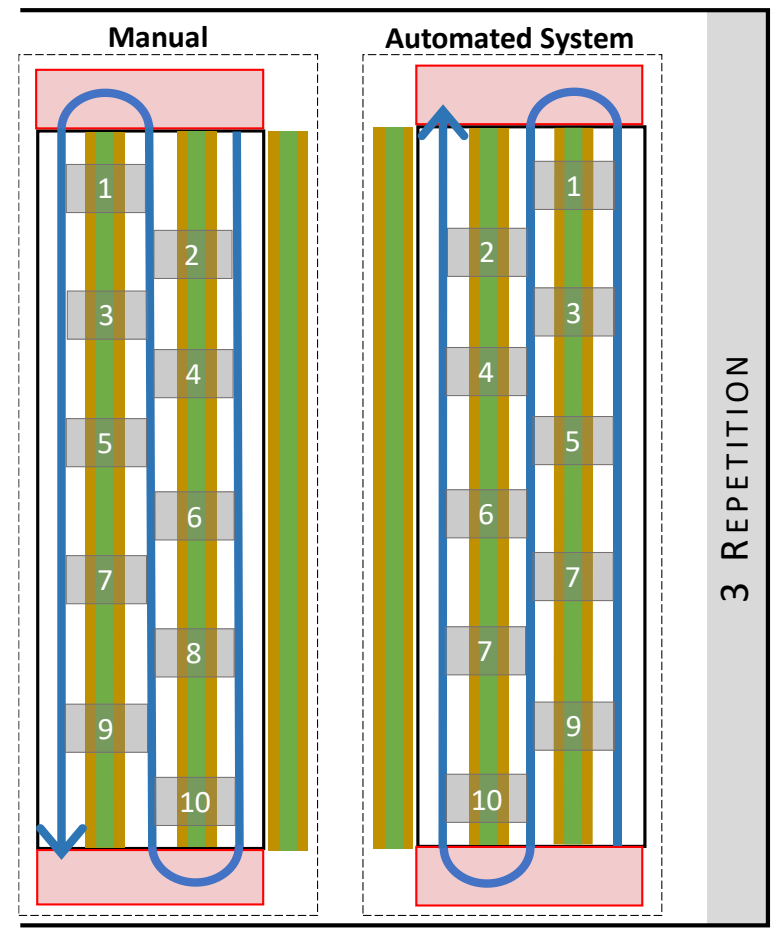

Manoeuvre time
Tillage time

Tillage quality plot

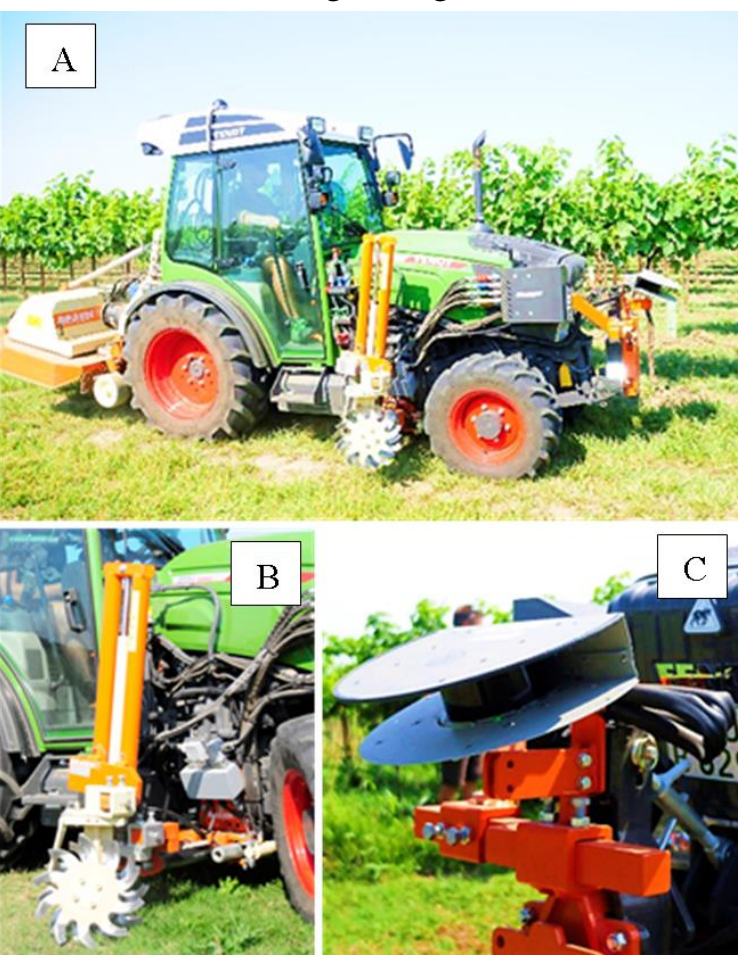

Fig. 2. Working configuration (A) with tillage implement $(B)$ and sensor $(C)$

Manual and automated mechanical weeding performances were evaluated considering working time recorder manually with stopwatches. Quality of tillage operation was assessed considering the distance of tilled soil from the vine row. Effects of the automated system on the tillage equipment movements was assessed with two dataloggers composed by an accelerometer (LIS3DH, STMicroelectronics NV, Geneva Switzerland) and a GNSS receiver (GP3906-TLP, ADH Technology Co. Ltd., Taichung City 41454, Taiwan).

\section{Results and discussion}

The time study performed considering the tillage and manoeuvre time showed that the automated system for mechanical weeding was faster than the manual one (Table 1).

Time study of the performed test

Table 1

\begin{tabular}{|l|c|c|}
\hline \multicolumn{1}{|c|}{ Parameter } & Automated & Manual \\
\hline Tillage time, $\mathrm{s}$ & 94.0 & 133.0 \\
\hline Maneuver time, $\mathrm{s}$ & 43.0 & 61.0 \\
\hline Total time, $\mathrm{s}$ & 137.0 & 194.0 \\
\hline Tillage speed, $\mathrm{km} \cdot \mathrm{h}^{-1}$ & 14.0 & 9.9 \\
\hline
\end{tabular}


In the automated treatment the average speed during the tillage operation was $14.0 \mathrm{~km} \cdot \mathrm{h}^{-1}$, while in manual operations it was $9.9 \mathrm{~km} \cdot \mathrm{h}^{-1}$. With the VPA system tillage mechanical weeding was $29.4 \%$ faster than manual control of the tillage implement.

Higher speed in the automated system rather than the manual system led to an increased effective field capacity $\left(h a \cdot h^{-1}\right)$ [4]. Figure 3 shows the effective field capacity recorded during the trials. Effective field capacity was calculated considering the working and maneuver time. According to this, it is affected by the field shape, dimension and row space.

Relative distance of tilled soil from the vines row was measured aiming to evaluate the quality of the automated and manual system in each tillage quality plot (Figure 1). Manual systems showed a mean left/right length of tilled soil from vine of $8.1 \mathrm{~cm}$, while in the automated system the average tilled soil variation on the left and on the right from vine row was of $3.8 \mathrm{~cm}$. Figure 4 represents the statistical distribution of tilled soil length difference from the right and left of vines.

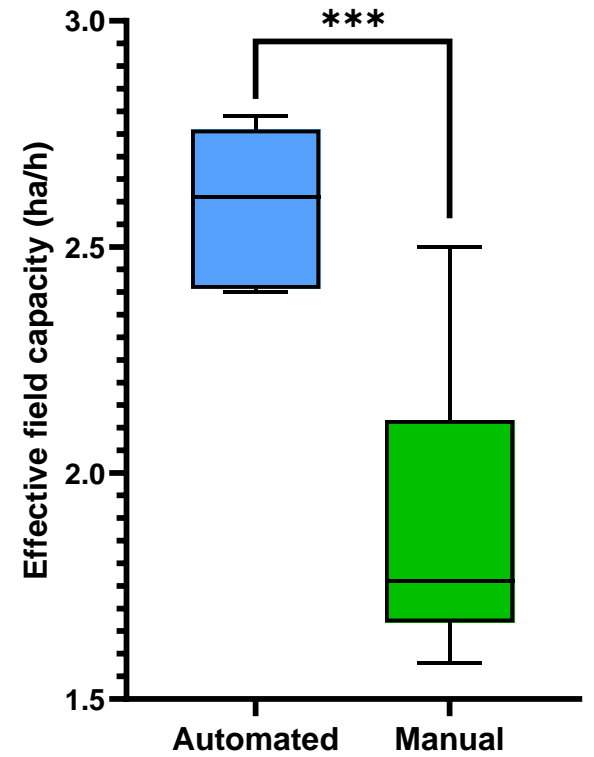

Fig. 3. Field capacity based on data recorded during the field test

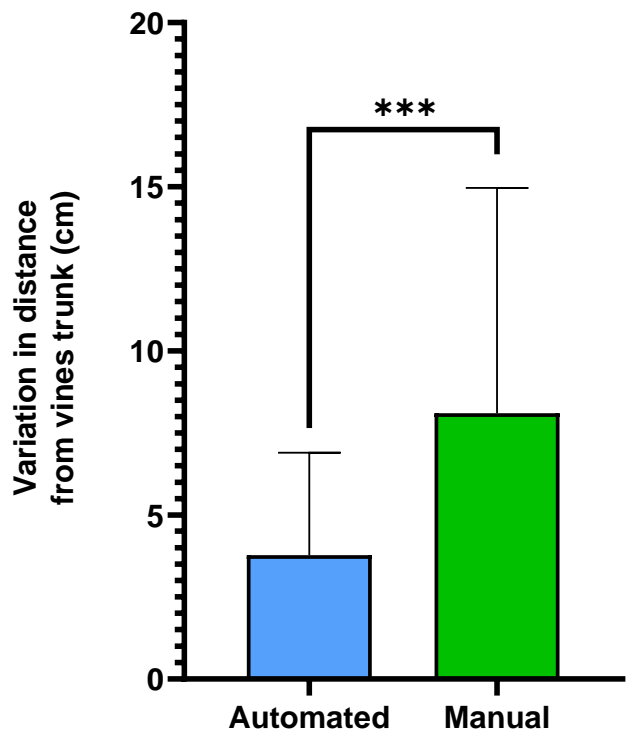

Fig. 4. Quality evaluation of tillage operations

The influence of the hydraulic cylinders on the implement position was evaluated with accelerometers mounted on the bracket, where the rotary star was attached. Effects of additional displacements performed by the hydraulic cylinder are shown in Figure 5.

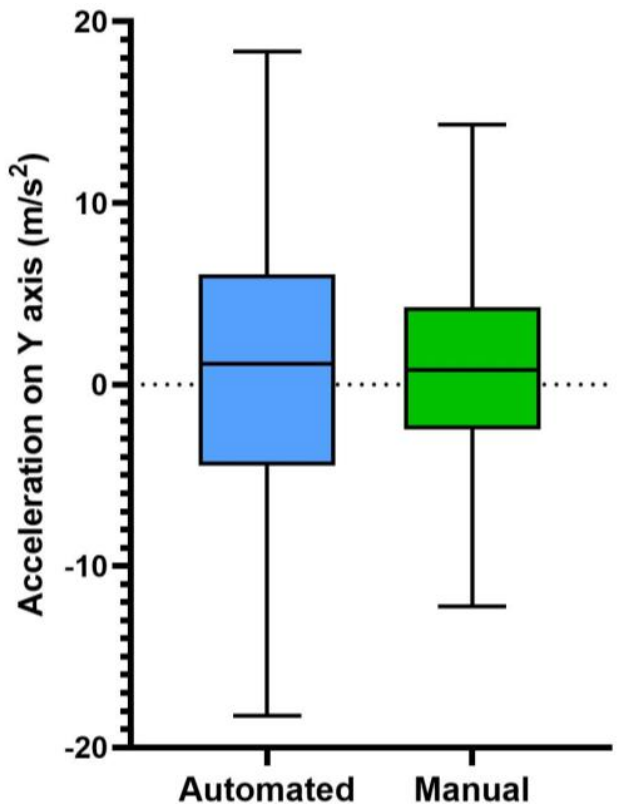

Fig. 5. Effects of hydraulic cylinders on the rotary star displacements 
Despite displacement exists even in the manual system, in the automated system the effects of hydraulic cylinders led to a high variance of acceleration ( $F$ test, $p$-value $<0.05$ ) in the direction of plants (perpendicular to the direction of forward motion). The displacements in the manual system may be caused by driver steering.

\section{Conclusions}

In this study, an automated system for mechanical weeding was tested and compared with the manual system. Mechanical weeding equipment was composed of a rotary star tiller, which was ventrally mounted on a tractor. In the automated system, the tiller was partially moved by a hydraulic cylinder controlled by a LiDAR sensor mounted in front of the tractor to detect the vine trunk position. In the manual system, the tiller was rigidly fixed to the tractor chassis. Performances were evaluated measuring the time of each operation, distance of tilled soil and acceleration in the direction of the hydraulic cylinder displacements. According to the results, the sensor driver implement allows an increment of the working speed of $29.4 \%$ resulting in a higher field capacity, compared with the manual system. At the same time, the average variation of tilled soil decreases by $-43.1 \%$ using the automated system resulting in more uniform tillage operation in close proximity of vines. The effect of the hydraulic cylinder on the rotary star tiller was significantly detected by the use of accelerometers. The results of this study showed that an automated system can be used to increase the field capacity and uniformity of mechanical weeding. In addition, such advantages may increase the application of automated implements in areas affected by a low mechanizability potential [10].

\section{Acknowledgements}

The authors would like to acknowledge Tenuta Civrana srl and Braun Macchine Agricole srl for their technical support and willingness.

\section{References}

[1] Manzone M., Demeneghi M., Marucco P., Grella M., Balsari P. Technical solutions for under-row weed control in vineyards: Efficacy, costs and environmental aspects analysis, J. Agric. Eng., vol. 51, no. 1, Mar. 2020, pp. 36-42.

[2] Steenwerth K. L., Belina K. M. Vineyard weed management practices influence nitrate leaching and nitrous oxide emissions, Agric. Ecosyst. Environ., vol. 138, no. 1-2, Jun. 2010, pp. 127-131.

[3] Yezekyan T., Olt J. Vineyard floor management with novel free-active inter-row tiller, 2016.

[4] Renoll E. Predicting Machine Field Capacity for Specific Field and Operating Conditions, Trans. ASAE, vol. 24, no. 1, 1981, pp. 0045-0047.

[5] Shrestha A., Kaan Kurtural S., Fidelibus M. W., Dervishian G., Konduru S., Efficacy and cost of cultivators, steam, or an organic herbicide for weed control in organic vineyards in the San Joaquin Valley of California, Horttechnology, vol. 23, no. 1, 2013, pp. 99-108.

[6] Slaughter D. C., Giles D. K., Downey D. Autonomous robotic weed control systems: A review, Comput. Electron. Agric., vol. 61, no. 1, Apr. 2008, pp. 63-78.

[7] Sozzi M. et al., On-the-go variable rate fertilizer application on vineyard using a proximal spectral sensor, in 2020 IEEE International Workshop on Metrology for Agriculture and Forestry (MetroAgriFor), 2020, pp. 343-347.

[8] Sozzi M., Kayad A., Tomasi D., Lovat L., Marinello F., Sartori L. Assessment of grapevine yield and quality using a canopy spectral index in white grape variety, in Precision Agriculture $2019-$ Papers Presented at the 12th European Conference on Precision Agriculture, ECPA 2019, 2019, pp. 181-186.

[9] Bähr O. Rolling cultivator, EP3412124A1, 2018.

[10] Cogato A., Pezzuolo A., Sørensen C. G., De Bei R., Sozzi M., Marinello F. A GIS-Based Multicriteria Index to Evaluate the Mechanisability Potential of Italian Vineyard Area, Land, vol. 9 , no. 11 , Nov. 2020, p. 469. 